\title{
Cost comparisons of endoscopic and surgical resection of stage $T 1$ rectal cancer
}

\section{(ㄷ)(1)}

Authors

Victoria Arthursson ${ }^{1}$, Roberto Rosén ${ }^{1}$, Jenny M. Norlin², Katarina Gralén², Ervin Toth ${ }^{3}$, Ingvar Syk ${ }^{1}$, Henrik Thorlacius ${ }^{1}$, Carl-Fredrik Rönnow ${ }^{1}$

Institutions

1 Department of Clinical Sciences, Malmö, Section of Surgery, Skåne University Hospital, Lund University, Malmö, Sweden

2 The Swedish Institute for Health Economics, Lund, Sweden

3 Department of Clinical Sciences, Section of Gastroenterology, Skåne University Hospital, Lund University, Malmö, Sweden

submitted 25.1.2021

accepted after revision 19.5 .2021

Bibliography

Endosc Int Open 2021; 09: E1512-E1519

DOI 10.1055/a-1522-8762

ISSN 2364-3722

(c) 2021. The Author(s).

This is an open access article published by Thieme under the terms of the Creative Commons Attribution-NonDerivative-NonCommercial License, permitting copying and reproduction so long as the original work is given appropriate credit. Contents may not be used for commercial purposes, or adapted, remixed, transformed or built upon. (https://creativecommons.org/licenses/by-nc-nd/4.0/)

Georg Thieme Verlag KG, Rüdigerstraße 14,

70469 Stuttgart, Germany

Corresponding author

Carl-Fredrik Rönnow, MD, PhD, Section of Surgery,

Department of Clinical Sciences, Malmö, Skåne University

Hospital, Lund University, 20502 Malmö, Sweden

Fax: +00+46-40-336207

carl-fredrik.ronnow@med.lu.se

\section{ABSTRACT}

Background and study aims Management of $\mathrm{T} 1$ rectal cancer is complex and includes several resection methods, making cost comparisons challenging. The aim of this study was to compare costs of endoscopic and surgical resection and to investigate hypothetical cost scenarios for the treatment of $\mathrm{T} 1$ rectal cancer.

Patients and methods Retrospective population-based cost minimization study on prospectively collected data on T1 rectal cancer patients treated using endoscopic submucosal dissection (ESD), transanal endoscopic microsurgery (TEM), open, laparoscopic, or robotic resection, in Skåne County, Sweden (2011-2017). The hypothetical cost scenarios were based on the distribution of high-risk features of lymph node metastases in a national cohort (20092017).

Results Eighty-five patients with T1 RC undergoing ESD (n $=16)$, TEM $(n=17)$, open $(n=35)$, laparoscopic $(n=9)$, and robotic $(n=8)$ resection were included. ESD had a total 1 year cost of $5165 €$ and was significantly $(P<0.05)$ less expensive compared to TEM (14871€), open (21453€), laparoscopic (22488€) and robotic resection (26562€). Risk factors for lymph node metastases were seen in $68 \%$ of 779 cases of $\mathrm{T} 1$ rectal cancers included in the national cohort. The hypothetical scenario of performing ESD on all T1 RC had the lowest total 1-year per patient cost compared to all other alternatives.

Conclusions This is the first study analyzing total 1-year costs of endoscopic and surgical methods to resect $\mathrm{T} 1 \mathrm{rec}$ tal cancer, which showed that the cost of ESD was significantly lower compared to TEM and surgical resection. In fact, based on hypothetical cost scenarios, ESD is still justifiable from a cost perspective even when all high-risk cases are followed by surgery in accordance to guidelines.

\section{Introduction}

Colorectal cancer is the third most common cancer in the Western world and nearly $35 \%$ of these tumors are located in the rectum [1]. Multiple therapeutic alternatives are available for treating early $\mathrm{T} 1$ rectal cancer, including local endoscopic resection methods such as endoscopic submucosal dissection
(ESD) and transanal endoscopic microsurgery (TEM) as well as rectal surgery by open, laparoscopic or robotic resection [2$6]$. Local resection of early rectal cancer is beneficial for patients in terms of preserved bowel function and decreased morbidity and mortality as compared to surgery [7-9]. However, the risk of lymph node metastasis (LNM) limits local resection as final treatment to cases with a low risk of LNM. Current 
guidelines recommend additional surgery after radical local excision of T1 rectal cancer if one or more of the following histopathological features are present; deep submucosal invasion (>Sm1), lymphovascular involvement (LVI), tumor budding and poor differentiation [6]. Surgery is in general first-line treatment when malignancy is confirmed, since pretherapeutic staging of LNM risks in rectal lesions is notoriously difficult. Thus, local resection is largely confined to unclear cases with cancer negative biopsies and patients with high age or aggravating comorbidities. With escalating health care costs due to demographic changes and new expensive and minimal invasive technologies there is an increased need for cost comparisons between alternative methods [10,11]. Previous studies have shown that ESD is less expensive than TEM, due to avoidance of anesthesia and shorter hospital stay $[12,13]$. In regards of treatment equality, the literature shows that ESD and TEM result in similar en bloc and $\mathrm{R} 0$ resection rates for malignant rectal lesions [13-15]. As for the surgical alternatives, a recent study showed that robotic rectal resection is more expensive than both open and laparoscopic resection without any additional benefit for patients [16]. Notably, previous studies have shown that both ESD and TEM are more cost-effective compared to surgical resection [17-19]. However, cost comparisons of endoscopic and surgical resection are challenging because the proportion of cases requiring subsequent surgery after local resection significantly influences the total cost of treating patients with early rectal cancer.

Based on the considerations above, the primary aim of this study was to compare the total 1-year costs of endoscopic and surgical methods to resect T1 RC, including costs of intensified follow-up and subsequent surgery in the local resection groups as well as costs for conversion of temporary ileostomies in the surgical resection groups. The secondary aim was to investigate hypothetical cost scenarios of performing local resection as initial treatment on all T1 RC, followed by surgery on all cases with high risk of LNM.

\section{Patients and methods}

All patients with T1 rectal cancer treated in Skåne County (approximately 1.4 million inhabitants) between 2011 and 2017 were identified in the Swedish Colorectal Cancer Registry, a national quality registry containing prospectively registered data. During the study period, the coverage compared to the compulsory Swedish Cancer Registry was $99 \%$ for rectal cancer. Patients with T1 rectal cancer undergoing ESD, TEM, open, laparoscopic or robotic resection as primary treatment were included in this study. Patients with synchronous lesions, hereditary forms of rectal cancer as well as patients receiving neo-adjuvant treatment and patients treated in but residing outside Skåne County were excluded. Patients were assigned to one of five groups, according to the primary treatment method (ESD, TEM, open, laparoscopic or robotic resection). Hence, cases converted from laparoscopic or robotic resection to open resection as well as cases undergoing subsequent surgery after local resection were kept within their initial study group. Clinical record forms were created for the procedural period, includ- ing all events from admission to discharge and the follow-up period including all events from discharge up to 1 year after the procedure. In case of subsequent surgery after local resection due to severe pathology, an additional clinical record form was completed and the 1-year follow-up period was extended to include 1 year from the final procedure. An additional clinical record form was also completed in case of complications requiring surgery and for conversion of loop ileostomies. The Charlson comorbidity index was used to compare the disease burden between the groups [20]. The Clavien-Dindo classification of surgical complications was adopted to score adverse events [21].

\section{Preoperative workup, procedures and postoperative care}

All biopsy-confirmed or suspected cancers were discussed at a preoperative multidisciplinary team conference. Local resection was chosen in unclear cases with cancer negative biopsies as well as selected cases of confirmed rectal cancers in elderly and comorbid patients and open, laparoscopic or robotic resection were chosen in the remaining cases, at the discretion of the multidisciplinary team conference. All surgical resections were performed as total mesorectal excisions, either by anterior resections or abdominoperineal resections (open, laparoscopic or robotic). All TEM procedures were full-thickness resections and all ESD procedures were performed with submucosal dissection using fluid injections and a cautery knife as described previously [22]. Postoperative care of surgical patients was provided at dedicated colorectal surgery wards following standardized enhanced recovery pathways.

\section{Cost analyses}

Cost-effectiveness analyses are based on costs and treatment effectiveness, often expressed as quality-adjusted life-years, which was not attainable in this study. Consequently, this is not a cost-effectiveness analysis but rather a cost-minimization analysis, which implies comparisons of costs for treatment alternatives that achieve a common outcome to an equal degree. This study includes analysis and comparisons of direct costs, comprising all costs related to the treatment and patient care. Indirect costs, defined as costs related to losses in patient productivity due to disease-related morbidity and mortality were not included since the median age in this study was higher than the retirement age in Sweden. Direct costs were estimated for the procedural and follow-up periods respectively. The procedural period included all events from admission to discharge and comprised costs of: radiologic imaging, procedurerelated (anesthesia, operating room time, consumable supplies, staff salary), daily hospitalization fee (medications, intravenous solutions, routine laboratory tests, and staff salary) as well as ancillary services as required.

Costs were derived from the Regional Price and Reimbursement List for the Southern Healthcare Region 2017 except for the procedural costs of open, laparoscopic and robotic resection, not included therein. Instead, a mean price for year 2017 was calculated for these procedures by the surgical department economist. Cases converted from laparoscopic or robotic re- 
section to open resection were submitted an extra cost (25\% of the procedure cost of open resection) to account for extra equipment, consumables as well as prolonged operating room time. Costs applied to the follow-up period included costs of: appointments at the surgical policlinic (nurse or doctor visits), radiologic imaging, endoscopic examination, consumables related to stoma care (based on a report from the Dental and Pharmaceutical Benefits Agency [23]), emergency-room visits, as well as subsequent surgery following non-curative local resections and conversion of diverting ileostomies. All costs were converted from Swedish krona (SEK) to Euro (EUR) using Sweden's central bank mean conversion rate for 2017 (1 EUR = 9.63 SEK).

\section{Hypothetical cost scenarios}

We used hypothetical cost scenarios to estimate the cost of different primary treatment strategies: 1 ) local resection on all T1 rectal cancers followed by subsequent surgery in all non-curative cases; or 2) surgery on all T1 rectal cancers as first and final treatment. Thus, we used a national cohort (Swedish Colorectal Cancer Registry) comprising all patients with $\mathrm{T} 1$ rectal cancer in Sweden, treated with surgery or local resection from 2009 to 2017. A low-risk group in which local excision can be deemed as final and curative treatment was defined as absence of the following high-risk features: deep submucosal invasion (> Sm1), LVI and poor/low tumor differentiation. The high-risk group was hence defined as cases with any of the aforementioned risk factors. This definition is coherent to current guidelines [6] except for not including tumor budding as a high-risk feature, since this parameter was not registered in the Swedish Colorectal Cancer Registry during the entire study period. Patients receiving neo-adjuvant treatment and patients with synchronous colorectal cancers as well as cases with missing data on depth of submucosal invasion, LVI or histologic grade were excluded. All pedunculated lesions were excluded by means of including only cases with registered depth of submucosal invasion because this parameter is not applicable to pedunculated lesions. Scenario analyses were conducted for each treatment alternative by using the median costs derived from the selection of patients treated in Skåne County and extrapolating them to the national cohort. The following assumptions were made: 1) all cases with high-risk features of LNM would undergo subsequent surgical resection, regardless of age and comorbidities; 2) all TEM or ESD resections were en-bloc and R0 in all T1 sm1 cases; and 3) patient characteristics, treatment patterns, and costs in the Skåne County cohort were representative of the national cohort. Total 1-year per-patient costs for all T1 cases were calculated for the following scenarios: 1) ESD or 2) TEM followed by subsequent surgery (calculated as median of the two less costly surgical resection alternatives) in all high-risk cases; 3) open resection as primary treatment; 4) laparoscopic resection as primary treatment; and 5) robotic resection as primary treatment.

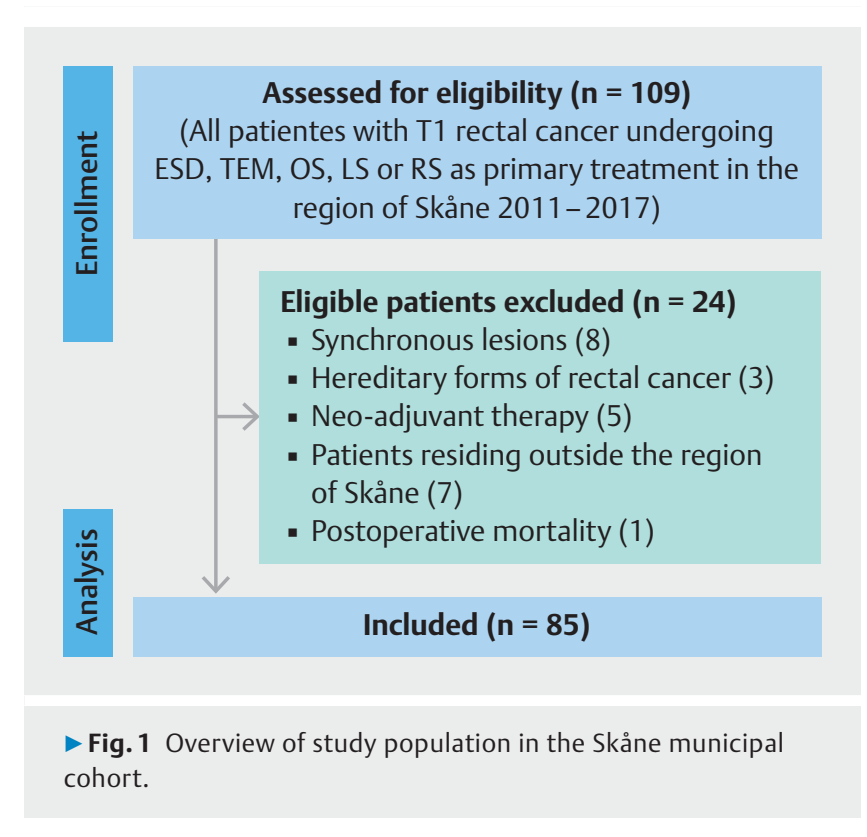

\section{Ethics}

This study was carried out in accordance with the ethical principles of the Declaration of Helsinki. Approval by the Regional Ethical Review Board, Lund University (2017/546) was granted prior to study start. Data retrieved from the Swedish Colorectal Cancer Registry were coded and patient anonymity was guaranteed.

\section{Statistics}

To test for differences in operating room time and hospitalization rate between the groups, the Kruskal-Wallis test was used. The Wilcoxon rank-sum (Mann-Whitney U) test was used to test for differences in costs between two treatment groups. Analyses were performed using STATA statistical software (release 14.2, College Station, Texas, United States).

\section{Results}

A total of 109 patients with T1 rectal cancer fulfilled the inclusion criteria, of whom 24 met the exclusion criteria and one patient died 2 days after open resection due to myocardial infarction and was also excluded ( $>$ Fig. $\mathbf{1}$ ). The remaining 85 patients with T1 rectal cancers undergoing, ESD $(n=16)$, TEM $(n=17)$, open $(n=35)$, laparoscopic $(n=9)$, and robotic resection $(n=8)$ constituted the study population. Median age was 69 years (38-89) and 47 of the participants (55\%) were men ( $>$ Table 1). Median age and body mass index (BMI) were lowest in the ESD group (age 64, BMI 26) and highest in the laparoscopic resection group (age 72, BMI 27), whereas median Charlson comorbidity index was the same (5) in all groups ( $>$ Table 1 ). Operating room time was highest in the robotic (465 minutes), followed by the laparoscopic (359 minutes) and open (264 minutes) resection groups and lowest for TEM (65 minutes), followed by ESD (83 minutes). The differences in operating room time were statistically significant $(P<0.05)$, except for the difference between ESD and TEM ( $\triangleright$ Table 1). Hospitalization 
- Table 1 Baseline characteristics in the five treatment groups.

\begin{tabular}{|c|c|c|c|c|c|c|}
\hline & $\begin{array}{l}\text { ESD } \\
(n=16)\end{array}$ & $\begin{array}{l}\text { TEM } \\
(n=17)\end{array}$ & $\begin{array}{l}\text { Open resection } \\
(\mathrm{n}=35)\end{array}$ & $\begin{array}{l}\text { Laparoscopic } \\
\text { resection } \\
(n=9)\end{array}$ & $\begin{array}{l}\text { Robotic } \\
\text { resection } \\
(n=8)\end{array}$ & $\begin{array}{l}\text { Total } \\
(n=85)\end{array}$ \\
\hline Age (years) & $64(44-89)$ & $70(62-79)$ & $68(38-86)$ & $72(59-80)$ & $69(60-76)$ & $69(38-89)$ \\
\hline Male (\%) & $9(56 \%)$ & $9(53 \%)$ & $19(54 \%)$ & $7(78 \%)$ & $3(38 \%)$ & $47(55 \%)$ \\
\hline BMI & $26(17-34)$ & $28(22-33)$ & $26(16-36.5)$ & $27(23-31)$ & $25(22-30)$ & $26(16-36.5)$ \\
\hline Charlson comorbidity index & $5(2-7)$ & $5(4-9)$ & $5(2-11)$ & $5(4-8)$ & $5(4-6)$ & $5(2-11)$ \\
\hline Hospitalization (days) & $0(0-3)$ & $2(0-15)$ & $10(6-24)$ & $7(5-28)$ & $9(6-28)$ & $7(0-28)$ \\
\hline Operating room time (min) & $83(18-594)$ & $65(25-234)$ & $264(152-398)$ & $359(245-554)$ & $465(341-692)$ & $241(18-692)$ \\
\hline
\end{tabular}

Presented as median and (range).

ESD, endoscopic submucosal dissection; TEM, transanal endoscopic microsurgery; BMI, body mass index.

- Table 2 Complications in the five treatment groups.

\begin{tabular}{|c|c|c|c|c|c|c|c|}
\hline & $\begin{array}{l}\text { Clavien- } \\
\text { Dindo }\end{array}$ & $\begin{array}{l}\text { ESD } \\
(n=16)\end{array}$ & $\begin{array}{l}\text { TEM } \\
(n=17)\end{array}$ & $\begin{array}{l}\text { Open resection } \\
(n=35)\end{array}$ & $\begin{array}{l}\text { Laparoscopic } \\
\text { resection } \\
(n=9)\end{array}$ & $\begin{array}{l}\text { Robotic } \\
\text { resection } \\
(n=8)\end{array}$ & $\begin{array}{l}\text { Total } \\
(n=85)\end{array}$ \\
\hline Perioperative perforation ${ }^{1}$ & 1 & 1 & & & & & 1 \\
\hline Perioperative perforation ${ }^{2}$ & II & 1 & 1 & & & & 2 \\
\hline Perioperative anastomotic leak & II & & & 2 & & & 2 \\
\hline Postoperative infection ${ }^{3}$ & II & & & 5 & 2 & & 7 \\
\hline Bowel paralysis & II & & 1 & 3 & 2 & 1 & 7 \\
\hline Acute renal failure & II & & & 1 & & & 1 \\
\hline Atrial fibrillation & II & & & & 1 & & 1 \\
\hline High stoma output & II & & & & & 1 & 1 \\
\hline Postoperative anastomotic leak & IIIa & & & & 1 & & 1 \\
\hline Pelvic Abscess & IIIa & & & 1 & & & 1 \\
\hline Subcutaneous wound rupture & IIIb & & & 1 & & & 1 \\
\hline Perforation of the small intestines & IVa & & & & 1 & & 1 \\
\hline Acute renal failure (dialysis) & IVa & & & 1 & & & 1 \\
\hline \multirow[t]{4}{*}{ Clavien-Dindo } & 1 & 1 & - & - & - & - & 1 \\
\hline & II & 1 & 2 & 11 & 5 & 2 & 22 \\
\hline & III & - & - & 2 & 1 & - & 3 \\
\hline & IV & - & - & 1 & 1 & - & 2 \\
\hline $\begin{array}{l}\text { ESD, endoscopic submucosal dissectio } \\
{ }^{1} \text { Closed with clip, no other treatment. } \\
{ }^{2} \text { Closed with clip (ESD) or suturing (TE } \\
{ }^{3} \text { Two cases of pneumonia, two cases o }\end{array}$ & $\begin{array}{l}\text { 1, transanal } \\
\text { olonged ob } \\
\text { is, one case }\end{array}$ & $\begin{array}{l}\text { scopic mic } \\
\text { tion and a } \\
\text { ostridium }\end{array}$ & irgery. & & & & \\
\hline
\end{tabular}

rates also differed significantly between the groups $(P<0.001)$ ( $\vee$ Table 1). Thirteen of the 16 ESD patients were treated as outpatients in contrast to the other groups in which all patients were hospitalized with the lowest and highest median hospitalization stay in the TEM ( 2 days) and open resection (10 days) groups, respectively ( $\downarrow$ Table $\mathbf{1}$ ). In total, 12 of 52 patients in the surgical resection groups received a permanent colostomy, 10 in the open resection group (10/35) and two in the robotic resection group (2/8). In addition, 33 of 52 patients received a diverting ileostomy, 20 in the open resection group (20/35), seven in the laparoscopic group (7/9), and six in the robotic re- 
section group (6/8). All but one of the 33 diverging ileostomies were converted during the 1 -year follow-up period.

Median tumor size was $4 \mathrm{~cm}$ (range $3-7 \mathrm{~cm}$ ) in the ESD group, $5 \mathrm{~cm}$ (range $4-10 \mathrm{~cm}$ ) in the TEM group and not stated for the surgical patients. High-risk features of LNM were observed in 11 of 16 ESD cases and in seven of 17 TEM cases, due to deep submucosal invasion (>Sm1) in nine ESD cases and six TEM cases and LVI in two ESD cases and one TEM case. Additional surgery, however, was only carried out in three of nine ESD patients with high-risk features ( 1 open, 2 robotic resections) and two of six high-risk TEM patients (2 robotic resections) because of patient reluctance to undergo surgery, aggravating comorbidity, or advanced age. All ESD and TEM cases were enbloc and R0 in the lateral and vertical margins in all Sm 1 cases. Three patients in the robotic resection group (3/8) and three patients in the laparoscopic resection group (3/9) were converted to open resection intra-operatively. Twenty-eight complications occurred in 21 of 85 patients, of which, the majority (23 of 28) were Clavien-Dindo I or II ( Table 2). Two patients required emergency surgery due to complications, one patient in the laparoscopic resection group, due to a perforation of the small intestine and one in the open resection group due to incisional dehiscence. In total, two patients were admitted to the intensive care unit: the patient in the laparoscopic resection group with perforation of the small intestine and one patient in the open resection group suffering from pneumonia, postoperative ileus and acute renal failure.

\section{Cost analyses}

The median direct costs for the respective procedures, comprising all costs from admission to discharge, follow-up costs (all costs from discharge to 1-year after the procedure) and total 1-year costs, are shown in > Table 3. ESD was significantly less expensive, both in regard to procedural costs and total 1year costs compared to the other groups ( $\triangleright$ Table 4 ). The procedural costs for TEM were significantly lower compared to open and robotic resection but not compared to laparoscopic resection ( $>$ Table 4 ). The total cost for TEM, however, was significantly lower compared to all three surgical alternatives ( $\triangleright$ Table 4). The procedural and total costs were significantly lower for open compared to robotic resection but not laparoscopic resection and there was no statistically significant difference between laparoscopic and robotic resection in regards of procedural or total costs ( $>$ Table 4 ).

\section{Hypothetical cost scenarios}

A total of 1514 surgically resected and 273 locally resected T1 rectal cancers were identified, of which 1008 were excluded due to neoadjuvant treatment $(n=208)$, synchronous cancers $(n=137)$, and missing data on depth of submucosal invasion, LVI and differentiation grade $(n=663)$. The remaining 779 patients with T1 rectal cancer constituted the national study cohort, consisting of 449 men (57\%) with a median age of 70 years (31-96). In total, 531 of 779 (68\%) included T1 rectal cancers had one or more risk factors for LNM (deep submucosal invasion (>Sm1), LVI and poor tumor differentiation) consisting of 35 patients in the local resection group (35/90, 39\%) and
- Table 3 Costs in the five treatment groups.

\begin{tabular}{|c|c|c|c|}
\hline & $\mathbf{n}$ & Median $(€)$ & $\operatorname{IQR}(€)$ \\
\hline \multicolumn{4}{|l|}{ ESD } \\
\hline - Procedure & 16 & 2650 & $2650-2650$ \\
\hline - Follow-up & & 1979 & 899-2904 \\
\hline - Total cost & & 5165 & $3964-5781$ \\
\hline \multicolumn{4}{|l|}{ TEM } \\
\hline - Procedure & 17 & 12736 & $12236-12736$ \\
\hline - Follow-up & & 1987 & $1342-3493$ \\
\hline - Total cost & & 14871 & $14550-17222$ \\
\hline \multicolumn{4}{|l|}{ Open resection } \\
\hline - Procedure & 35 & 14236 & 12734-17739 \\
\hline - Follow-up & & 5912 & $2479-8829$ \\
\hline - Total cost & & 21453 & $17902-24739$ \\
\hline \multicolumn{4}{|c|}{ Laparoscopic resection } \\
\hline - Procedure & 9 & 13831 & $11137-22063$ \\
\hline - Follow-up & & 6351 & $5223-10136$ \\
\hline - Total cost & & 22488 & $17262-27068$ \\
\hline \multicolumn{4}{|c|}{ Robotic resection } \\
\hline - Procedure & 8 & 21125 & $18611-25213$ \\
\hline - Follow-up & & 6541 & 3886-9819 \\
\hline - Total cost & & 26562 & $23537-36816$ \\
\hline \multicolumn{4}{|l|}{ Total } \\
\hline - Procedure & 85 & 13235 & $12234-17558$ \\
\hline - Follow-up & & 3493 & $1896-7635$ \\
\hline - Total cost & & 19807 & $14723-24688$ \\
\hline \multicolumn{4}{|c|}{$\begin{array}{l}\text { ESD, endoscopic submucosal dissection; TEM, transanal endoscopic micro- } \\
\text { surgery; } \\
\text { IQR, interquartile range ( } 25 \%-75 \%)\end{array}$} \\
\hline
\end{tabular}

496 patients in the surgical resection group (496/689, 72\%). The actual incidence of LNM in the surgical resection group was $84 / 689$ (12\%). The estimated total 1 -year costs for the different hypothetical scenarios are given in $>$ Table 5. ESD, followed by subsequent surgery for all non-curative resections ( $68 \%$ of all cases) was the least expensive scenario with a 1year cost of $18168 €$ per patient ( $>$ Table 5). TEM, followed by subsequent surgery for all non-curative resections $(68 \%$ of cases) was the most expensive scenario with a 1 -year cost of $28319 €$ per patient.

\section{Discussion}

There are several different methods to treat patients with T1 rectal cancer. This cost-minimization study compared costs of treating early rectal cancer with local endoscopic and surgical 
- Table 4 Comparisons of procedural and total 1-year costs.

\begin{tabular}{|c|c|c|c|c|c|c|c|}
\hline Procedural cost & vs & Procedural cost & & Total cost & vs & Total cost & \\
\hline \multirow[t]{4}{*}{$\begin{array}{l}\text { ESD } \\
(2650 €)\end{array}$} & & TEM & $P<0.001$ & $\begin{array}{l}\text { ESD } \\
(5165 €)\end{array}$ & & TEM & $P=0.001$ \\
\hline & & Open resection & $P<0.001$ & & & Open resection & $P<0.001$ \\
\hline & & Laparoscopic resection & $P<0.001$ & & & Laparoscopic resection & $P=0.003$ \\
\hline & & Robotic resection & $P<0.001$ & & & Robotic resection & $P=0.002$ \\
\hline \multirow[t]{3}{*}{$\begin{array}{l}\text { TEM } \\
(12736 €)\end{array}$} & & Open resection & $P=0.008$ & $\begin{array}{l}\text { TEM } \\
(14871 €)\end{array}$ & & Open resection & $P=0.001$ \\
\hline & & Laparoscopic resection & $P=0.722$ & & & Laparoscopic resection & $P=0.033$ \\
\hline & & Robotic resection & $P<0.001$ & & & Robotic resection & $P<0.001$ \\
\hline \multirow[t]{2}{*}{$\begin{array}{l}\text { Open resection } \\
(14236 €)\end{array}$} & & Laparoscopic resection & $P=0.630$ & $\begin{array}{l}\text { Open resection } \\
(21453 €)\end{array}$ & & Laparoscopic resection & $P=0.873$ \\
\hline & & Robotic resection & $P<0.001$ & & & Robotic resection & $P=0.010$ \\
\hline $\begin{array}{l}\text { Laparoscopic } \\
\text { resection } \\
(13831 €)\end{array}$ & & Robotic resection & $P=0.070$ & $\begin{array}{l}\text { Laparoscopic resection } \\
(22488 €)\end{array}$ & & Robotic resection & $P=0.070$ \\
\hline $\begin{array}{l}\text { Robotic resection } \\
(21125 €)\end{array}$ & & - & - & $\begin{array}{l}\text { Robotic resection } \\
(21125 €)\end{array}$ & & - & -- \\
\hline
\end{tabular}

resection. Local resection of T1 rectal cancer is beneficial compared to surgery in terms of reduced morbidity and mortality [7-9]. These benefits, however, are only attainable for T1 cancers with low risk of concomitant LNM. The economic aspects of local and surgical methods to resect $\mathrm{T} 1$ rectal cancer are elusive since the true costs of local resection not only comprise that of curative resections but also all non-curative cases with high risk of LNM requiring subsequent surgery. This study shows that ESD not only had a significant lower total 1-year cost compared to the surgical alternatives but was also more than four times less costly than TEM in regards of procedural cost. In addition, we found that $68 \%$ of all T1 rectal cancers exhibit high-risk features requiring surgical resection according to guidelines, although only $12 \%$ of the surgically treated patients actually had LNM. However, the hypothetical scenario of performing ESD on all $\mathrm{T} 1$ rectal cancers initially, followed by subsequent surgery on all patients with high-risk features, had considerably lower total 1-year cost compared to all other hypothetical scenarios.

The primary aims in this study were procedural and total 1year costs of five methods to resect $\mathrm{T} 1$ rectal cancer. We found that both the procedural and total 1-year costs related to ESD were significantly lower compared to the other alternatives. In fact, the procedural cost for TEM (12736 €) was more than four times higher than that for ESD (2650 €). TEM has previously been reported to have a higher cost compared to ESD and the big gap in costs between the two oncological equivalent treatments is related to the expensive TEM equipment, need for an operating room and anesthesia as well as longer hospitalization stays $[12,15]$. It should also be noted that although TEM comprises full-thickness resection and ESD implies submucosal re-
- Table 5 Hypothetical cost scenarios based on different index procedures on all T1 rectal cancers.

\begin{tabular}{|l|c|}
\hline Index procedure & Per patient 1-year cost \\
\hline ESD & $18168 €$ \\
\hline TEM & $28319 €$ \\
\hline Open resection & $21453 €$ \\
\hline Laparoscopic resection & $22488 €$ \\
\hline Robotic resection & $26562 €$ \\
\hline $\begin{array}{l}\text { Per patient 1-year costs were calculated for respective method as first-line } \\
\text { treatment, based on 779 T1 rectal cancers identified in the Swedish Colo- } \\
\text { rectal Cancer Registry 2009-2018, including costs of subsequent resection } \\
\text { (mean cost of open and laparoscopic resection) in 530 (68\%) high-risk cases } \\
\text { of lymph node metastases for ESD and TEM. } \\
\text { ESD, endoscopic submucosal dissection; TEM, transanal endoscopic micro- } \\
\text { surgery. }\end{array}$ \\
\hline
\end{tabular}

section, there are no oncological advantages or reduction in recurrence or LNM incidence associated with TEM. In fact, it has previously been reported that salvage surgery after TEM results in higher morbidity and higher rates of abdominoperineal resections and permanent stomas compared to performing surgery straightaway [24-27]. Thus, TEM-associated full-thickness resection can result in scarring and obliteration of the embryological planes, complicating surgical dissection [24-27]. Moreover, as expected, we found that the procedural and total costs of open resection were significantly lower than that for robotic resection, which is supported by numerous previous studies 
$[16,28,29]$. However, the difference in cost between laparoscopic and robotic resection in our study was not statistically significant. This finding is in contrast to previous studies showing that robotic resection is more costly than laparoscopic resection [16, 28, 30, 31]. This discrepancy could possibly be explained by the few cases in both the laparoscopic and robotic resection groups in our study, inducing a possible type-II error. Also, one of the patients in the laparoscopic group needed postoperative treatment in the Intensive Care Unit, following emergency surgery, which increased total cost in the laparoscopic group compared to the robotic group, in which no patient suffered serious complications. However, comparing costs of ESD and TEM with surgical resection in the present cost-minimization analysis is partially misleading, given that a majority of the high-risk TEM and ESD patients did not undergo subsequent surgery. We therefore performed hypothetical cost scenarios, to test the potential costs of ESD and/or TEM as initial treatment on all T1 rectal cancers, when all patients with highrisk features are followed by surgery, in accordance with guidelines [6].

We found that from 2009 to 2017 in Sweden, $68 \%$ of all T1 rectal cancers were high-risk tumors in terms of LNM risk and would require surgical resection according to guidelines [6]. In this context, it is important to note that the actual incidence of LNM in our study was $12 \%$ in the surgical resection group. Thus, adherence to guidelines results in unnecessary surgery in the majority of patients referred to surgery. The hypothetical scenario of performing ESD on all T1 rectal cancers followed by subsequent surgery on all non-curative resections $(68 \%$ of cases) was still associated with a lower cost compared to all other scenarios. The hypothetical scenario of performing TEM on all patients followed by subsequent surgery on all non-curative resections turned out to be the most expensive scenario of all and even more costly than performing robotic resection on all patients right away.

Our hypothetical cost scenarios are based on certain assumptions. First, that all local resections are en bloc and R0. As for both TEM and ESD, the procedures can be performed with an almost certainty of en bloc and R0 in the lateral margins and $\mathrm{RO}$ in the vertical margins in cases of shallow submucosal invasion and without size limitations in expert centers, as demonstrated herein and in previous studies [5, 32-35]. We also assumed that our initial Skåne County cohort was representative in terms of patient characteristics, treatment patterns, and costs, and applicable on both a national level and at a larger scale. Although length of hospital stay, complication rates, and timing of stoma conversions might differ, the total annual costs is assumed to vary only marginally based on these variables because costs are primarily driven by operating room time and equipment for the different surgical procedures.

Our study was limited by small case numbers in each group and its retrospective design, although data were collected prospectively. The five groups were equal in terms of comorbidity but not age, BMI, and gender and the possible impact of these factors on costs is unknown, which also limits our study. Another limitation is that determination of costs and actual treatment costs can vary between countries. The study was further limited by not including tumor budding as a high-risk feature in the hypothetical cost scenarios.

\section{Conclusions}

In conclusion, to the best of our knowledge, this was the first study to analyze total 1 -year costs of $\mathrm{T} 1$ rectal cancer treatment comparing methods for local and surgical resection. We found that the cost of ESD was significantly lower than that for all other alternatives. In fact, even when hypothetically all T1 rectal cancers were treated with ESD and followed by surgery in all high-risk patients, according to guidelines, ESD still had the lowest total cost for treating $\mathrm{T} 1$ rectal cancer.

\section{Competing interests}

Authors Norlin and Gralén received an unrestricted grant from Olympus Sweden.

References

[1] Fitzmaurice C, Allen C. Global Burden of Disease Cancer Collaboration. et al. Global, regional, and national cancer incidence, mortality, years of life lost, years lived with disability, and disability-adjusted life-years for 32 cancer groups, 1990 to 2015: a systematic analysis for the global burden of disease study. JAMA Oncol 2017; 3: 524-548

[2] Lacy AM, Garcia-Valdecasas JC, Delgado S et al. Laparoscopy-assisted colectomy versus open colectomy for treatment of non-metastatic colon cancer: a randomised trial. Lancet 2002; 359: 2224-2229

[3] Fleshman J, Sargent DJ, Green E et al. Laparoscopic colectomy for cancer is not inferior to open surgery based on 5-year data from the COST Study Group trial. Ann Surg 2007; 246: 655-662 discussion 662-654

[4] Memon S, Heriot AG, Murphy DG et al. Robotic versus laparoscopic proctectomy for rectal cancer: a meta-analysis. Ann Surg Oncol 2012; 19: 2095-2101

[5] Al-Najami I, Rancinger CP, Larsen MK et al. Transanal endoscopic microsurgery for advanced polyps and early cancers in the rectum-Longterm outcome: A STROBE compliant observational study. Medicine 2016; 95: e4732

[6] Pimentel-Nunes P, Dinis-Ribeiro M, Ponchon T et al. Endoscopic submucosal dissection: European Society of Gastrointestinal Endoscopy (ESGE) Guideline. Endoscopy 2015; 47: 829-854

[7] Zauber AG, Winawer S], O'Brien M] et al. Colonoscopic polypectomy and long-term prevention of colorectal-cancer deaths. N Engl J Med 2012; 366: 687-696

[8] Kim JB, Lee HS, Lee HJ et al. Long-term outcomes of endoscopic versus surgical resection of superficial submucosal colorectal cancer. Dig Dis Sci 2015; 60: 2785-2792

[9] Alves A, Panis Y, Mathieu P et al. Postoperative mortality and morbidity in French patients undergoing colorectal surgery: results of a prospective multicenter study. Arch Surg 2005; 140: 278-283 discussion 284

[10] Porter ME. What is value in health care? N Engl J Med 2010; 363: 2477-2481

[11] Barbash GI, Glied SA. New technology and health care costs-the case of robot-assisted surgery. N Engl J Med 2010; 363: 701-704 
[12] Nam M], Sohn DK, Hong CW et al. Cost comparison between endoscopic submucosal dissection and transanal endoscopic microsurgery for the treatment of rectal tumors. Ann Surg Treat Res 2015; 89: 202207

[13] McCarty TR, Bazarbashi AN, Hathorn KE et al. Endoscopic submucosal dissection (ESD) versus transanal endoscopic microsurgery (TEM) for treatment of rectal tumors: a comparative systematic review and meta-analysis. Surg Endosc 2020; 34: 1688-1695

[14] Wang S, Gao S, Yang W et al. Endoscopic submucosal dissection versus local excision for early rectal cancer: a systematic review and meta-analysis. Tech Coloproctol 2016; 20: 1-9

[15] Park SU, Min YW, Shin JU et al. Endoscopic submucosal dissection or transanal endoscopic microsurgery for nonpolypoid rectal high grade dysplasia and submucosa-invading rectal cancer. Endoscopy 2012; 44: 1031-1036

[16] Silva-Velazco J, Dietz DW, Stocchi L et al. Considering value in rectal cancer surgery: an analysis of costs and outcomes based on the open, laparoscopic, and robotic approach for proctectomy. Ann Surg 2017; 265: 960-968

[17] Law R, Das A, Gregory D et al. Endoscopic resection is cost-effective compared with laparoscopic resection in the management of complex colon polyps: an economic analysis. Gastrointest Endosc 2016; 83: $1248-1257$

[18] Fukami N. Surgery versus endoscopic mucosal resection versus endoscopic submucosal dissection for large polyps: making sense of when to use which approach. Gastrointest Endosc Clin N Am 2019; 29: 675-685

[19] Maslekar S, Pillinger SH, Sharma A et al. Cost analysis of transanal endoscopic microsurgery for rectal tumours. Colorectal Dis 2007; 9: 229-234

[20] Brusselaers N, Lagergren J. The Charlson Comorbidity Index in Registry-based Research. Methods Inf Med 2017; 56: 401-406

[21] Dindo D, Demartines N, Clavien PA. Classification of surgical complications: a new proposal with evaluation in a cohort of 6336 patients and results of a survey. Ann Surg 2004; 240: 205-213

[22] Thorlacius H, Uedo N, Toth E. Implementation of endoscopic submucosal dissection for early colorectal neoplasms in Sweden. Gastroenterol Res Pract 2013; 2013: 758202

[23] Svensson M, Nilsson F. The Swedish Dental and Pharmaceutical Benefits Agency's willingness to pay for new drugs has been analyzed. Lakartidningen 2016; 113: DX44
[24] Morino M, Allaix ME, Arolfo S et al. Previous transanal endoscopic microsurgery for rectal cancer represents a risk factor for an increased abdominoperineal resection rate. Surg Endosc 2013; 27: 3315-3321

[25] Hahnloser D, Wolff BG, Larson DW et al. Immediate radical resection after local excision of rectal cancer: an oncologic compromise? Dis Colon Rectum 2005; 48: 429-437

[26] Piessen G, Cabral C, Benoist S et al. Previous transanal full-thickness excision increases the morbidity of radical resection for rectal cancer. Colorectal Dis 2012; 14: 445-452

[27] Bulut O, Levic K, Hesselfeldt P et al. The outcome of rectal cancer after early salvage TME following TEM compared with primary TME: a casematched study. Tech Coloproctol 2014; 18: 83-84

[28] Dobson MW, Geisler D, Fazio V et al. Minimally invasive surgical wound infections: laparoscopic surgery decreases morbidity of surgical site infections and decreases the cost of wound care. Colorectal Dis 2011; 13: 811-815

[29] Fleshman J, Branda M, Sargent D] et al. Effect of laparoscopic-assisted resection vs open resection of stage II or III rectal cancer on pathologic outcomes: The ACOSOG Z6051 Randomized Clinical Trial. JAMA 2015; 314: 1346-1355

[30] Keller DS, Senagore A], Lawrence JK et al. Comparative effectiveness of laparoscopic versus robot-assisted colorectal resection. Surg Endosc 2014; 28: 212-221

[31] Park E], Cho MS, Baek S] et al. Long-term oncologic outcomes of robotic low anterior resection for rectal cancer: a comparative study with laparoscopic surgery. Ann Surg 2015; 261: 129-137

[32] Saito Y, Uraoka T, Yamaguchi Y et al. A prospective, multicenter study of 1111 colorectal endoscopic submucosal dissections (with video). Gastrointest Endosc 2010; 72: 1217-1225

[33] Ronnow CFUN, Toth E, Thorlacius H. Endoscopic submucosal dissection of 301 large colorectal neoplasias: outcome and learning curve from a specialized Western center. Endosc Int Open 2018; 11: E1340E1348

[34] Spychalski M, Skulimowski A, Dziki A et al. Colorectal endoscopic submucosal dissection (ESD) in the West - when can satisfactory results be obtained? A single-operator learning curve analysis Scand J Gastroenterol 2017; 52: 1442-1452

[35] Saclarides TJ. Transanal endoscopic microsurgery. Clin Colon Rectal Surg 2015; 28: 165-175 